\title{
Molecular phylogeny of the family Vorticellidae (Ciliophora, Peritrichia) using combined datasets with a special emphasis on the three morphologically similar genera Carchesium, Epicarchesium and Apocarchesium
}

\author{
Ping Sun, ${ }^{1}$ John C. Clamp, ${ }^{1}$ Dapeng $\mathrm{Xu}^{1}{ }^{1}$ Yasushi Kusuoka ${ }^{2}$ \\ and Manabu Hori ${ }^{3}$ \\ ${ }^{1}$ Department of Biology, North Carolina Central University, Durham, NC 27707, USA \\ ${ }^{2}$ Lake Biwa Museum, Oroshimo 1091, Kusatsu, Shiga 525-0001, Japan \\ ${ }^{3}$ Biological Institute, Faculty of Science, Yamaguchi University, Yamaguchi 753-8512, Japan
}

Correspondence

Ping Sun

psun@nccu.edu

\begin{abstract}
Little is known about the phylogeny of the family Vorticellidae at the generic level because few comprehensive analyses of molecular phylogenetic relationships between members of this group have, so far, been done. As a result, the phylogenetic positions of some genera that were based originally on morphological analyses remain controversial. In the present study, we performed phylogenetic analyses of vorticellids based on the sequence of the small-subunit (SSU) rRNA gene, including one species of the genus Apocarchesium, for which no sequence has previously been reported. Phylogenetic trees were reconstructed with SSU rRNA gene sequences by using four different methods (Bayesian analysis, maximum-likelihood, neighbour-joining and maximumparsimony) and had a consistent branching pattern. Members of the genera Vorticella (except $V$. microstoma) and Carchesium formed a clearly defined, well supported clade that was divergent from the clade comprising members of the genera Pseudovorticella and Epicarchesium, suggesting that the differences in the silverline system (transverse vs reticulate) among vorticellids may be the result of genuine evolutionary divergence. Members of the newly established genus Apocarchesium clustered within the family Vorticellidae basal to the clade containing members of the genera Pseudovorticella and Epicarchesium and were distinct from members of the genus Carchesium, supporting the validity of Apocarchesium as a novel genus. Additional phylogenetic analyses of 21 strains representing seven genera from the families Vorticellidae and Zoothamniidae were performed with single datasets (ITS1-5.8S-ITS2, ITS2 alone) and combined datasets (SSU rRNA + ITS1-5.8S-ITS2, SSU rRNA + ITS2) to explore further the phylogenetic relationship between the three morphologically similar genera Carchesium, Epicarchesium and Apocarchesium, using characteristics not included in previous analyses. The phylogenetic trees reconstructed with combined datasets were more robust and therefore more reliable than those based on single datasets and supported the results of trees based on SSU rRNA sequences.
\end{abstract}

\section{INTRODUCTION}

Peritrichs are a very large assemblage of distinctive ciliates that were first reported by van Leeuwenhoek over 300 years ago (Kahl, 1935). Traditionally, determining phylogenetic

\footnotetext{
Abbreviations: Bl, Bayesian; ML, maximum-likelihood; MP, maximumparsimony; NJ, neighbour-joining; SSU, small-subunit.

The GenBank/EMBL/DDBJ accession numbers for the SSU rRNA gene sequences determined in the present study are shown in Table 2.

Two supplementary figures and one supplementary table are available with the online version of this paper.
}

relationships among peritrichs has relied on comparing differences in their morphological characteristics; in particular the mode of development of the feeding stage (solitary or colonial), the structure of the stalk or lorica, the appearance of the oral area and the pattern of the silverline system (Corliss, 1979), which has been used widely as a diagnostic characteristic to distinguish between families and/or genera. Historically, peritrichs were assigned to the subclass Peritrichia Stein, 1859, within the class Oligohymenophora (Lynn, 2008). The subclass Peritrichia was thought to be a monophyletic assemblage composed of the orders Sessilida and Mobilida based on the characteristics 
of the oral apparatus (Lom, 1964; Lynn, 2008). Recent analyses using SSU rRNA sequences (Gong et al., 2006), however, revealed that mobilids do not group with sessilids and that their distinctive similarity in oral morphology is a convergently evolved characteristic. Removal of mobilids from the subclass Peritrichia (Zhan et al., 2009) left the former sessilids as the only true monophyletic group of taxa within the subclass.

The family Vorticellidae is one of the most morphologically and ecologically diverse groups within the subclass Peritrichia, containing 18 genera and at least 200 species of ciliates isolated from marine, limnetic and terrestrial habitats throughout the world (Corliss, 1979; Lynn, 2008; Warren, 1986). Members of the family are differentiated from other peritrichs by having a helically contractile spasmoneme within the stalk (Fig. 1a, d, e; indicated by arrows) and, historically, have been considered to be a welldefined group based on this characteristic. Within the family Vorticellidae, mode of development (solitary vs colonial) was the characteristic first used to differentiate members of one genus from another. The genus Vorticella contains $\sim 82$ species, all of which have a solitary mode of development (Warren, 1986). By contrast, the genus Carchesium (Fig. 1c, d) was established by Ehrenberg (1831) to group species that have a helically contractile stalk, like that of species of the genus Vorticella, but form branched colonies in which the spasmonemes are discontinuous between zooids. Members of the genus Apocarchesium (Fig. 1a, b) are colonial, like members of the genus Carchesium, but form colonies that consist of only a cluster of unbranched zooids at the tip of the primary stalk (Ji \& Kusuoka, 2009).

During the last few decades, the pattern of the silverline system (the pellicular ridges that mark the surface of the cell, which can be revealed by silver staining) has been used to define some genera of vorticellids. The genus Pseudovorticella was established by Foissner \& Schiffmann (1974) to group solitary vorticellids that were similar to species of the genus Vorticella but had a reticulate pattern of silverlines as opposed to the transverse pattern seen in species of the genus Vorticella. Also, the genus Epicarchesium (Fig. 1e, f) was established by Jankowski (1975) to include colonial forms of vorticellid that were similar to members of the genus Carchesium but, like members of the genus Pseudovorticella, had a reticulate silverline system. Descriptions of these genera were emended (Leitner \& Foissner, 1997) to include features of the oral infraciliature (e.g. the detailed arrangement of the three infundibular polykineties depicted in Fig. $1 \mathrm{~g}-\mathrm{i}$ ) as an essential diagnostic character.

Recently, molecular information from one gene, coding for small-subunit (SSU) rRNA, has been used to re-evaluate phylogenetic relationships among vorticellids, which has significantly advanced our understanding of the diversity within the group (Miao et al., 2001, 2004; Williams \& Clamp, 2007; Utz \& Eizirik, 2007; Li et al., 2008). In some cases, however, these molecular analyses have yielded radically different results from morphologically-based taxonomic studies of vorticellids. For example, in molecular studies, the genus Carchesium always grouped with the Vorticellidae-Astylozoidae-Opisthonectidae clade of families at a very deep level but was also closely associated with Zoothamnium arbuscula of the family Zoothamniidae in previous studies (Clamp \& Williams, 2006; Utz \& Eizirik, 2007; Williams \& Clamp, 2007; Li et al., 2008). Similarly, Vorticella microstoma was deeply divergent from its congeners in molecular studies and clustered with species of the genera Opisthonecta and Astylozoon, both of which are the type genus of separate families in morphology-based classifications; also, the SH test (Shimodaira \& Hasegawa, 1999) strongly rejected the inclusion of $V$. microstoma as a member of the genus Vorticella (Utz \& Eizirik, 2007).

Some vorticellid taxa with ambiguous systematic positions based on morphology have never been investigated by molecular methods. For example, members of the genus Apocarchesium would be identified as belonging to the genus Carchesium except for their anomalous mode of development. Species in the former genus differ from those in the latter by forming colonies with no secondary branches, existing as a tight cluster of zooids on the tip of the primary stalk. Also, they possess macrozooids, a characteristic of some species of the genus Zoothamnium that calls the phylogenetic position and taxonomic validity of the genus Apocarchesium into question. At present, a high degree of morphological diversity makes it difficult to determine which characteristics are a result of convergent evolution. A relatively small number of taxa are included in phylogenetic analyses and only one molecular marker, the SSU rRNA gene, has, so far, been used in molecular analyses (Clamp \& Williams, 2006; Williams \& Clamp, 2007; Li et al., 2008). Because of these limitations, the phylogeny of the family Vorticellidae remains largely unresolved.

In the present study, we obtained 15 new SSU rRNA gene sequences from seven species of the family Vorticellidae to clarify and expand our understanding of the phylogenetic relationships within this family. In addition to this, sequence analyses of the SSU rRNA gene and ITS1-5.8S-ITS2 and ITS2 regions of 21 strains of the families Vorticellidae and Zoothamniidae, in which the genes were either concatenated or treated individually, were performed to assess phylogenetic relationships between the morphologically similar genera Carchesium, Epicarchesium and Apocarchesium. The ITS2 and ITS1-5.8S-ITS2 regions were chosen because there is increasing evidence that analysis based on these markers and their secondary structures can provide a higher level of resolution when determining phylogenies focusing on relationships within and between families or genera of ciliates (Coleman, 2005; Miao et al., 2008).

\section{METHODS}

Collection and fixation of samples. All species in this study were collected from freshwater habitats in the USA, China and Japan (Table 1). Isolation, culturing and fixation of ciliates were performed according to the methods of Clamp \& Williams (2006). 

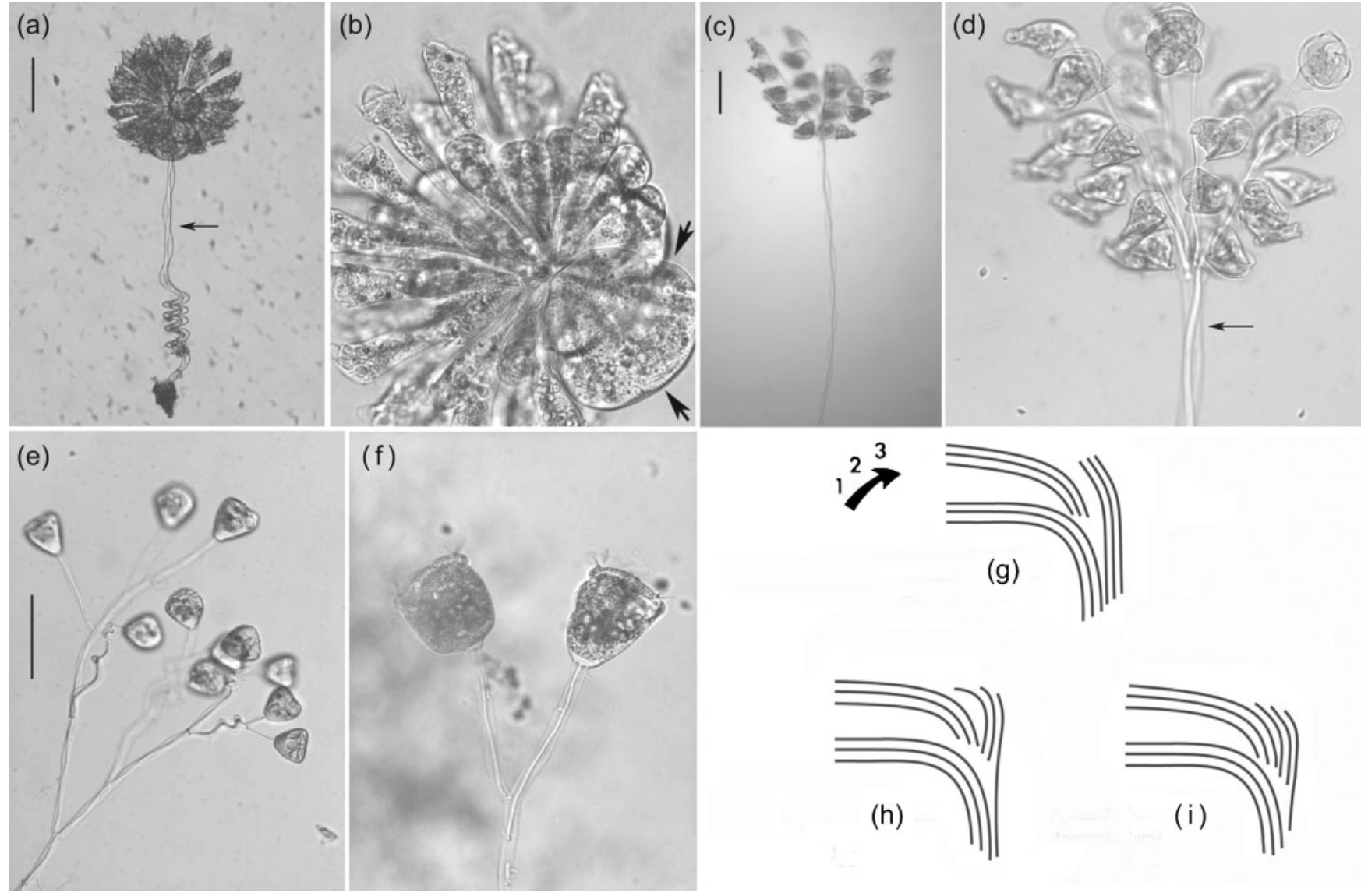

Fig. 1. Photomicrographs of species of Carchesium, Epicarchesium and Apocarchesium. (a, b) Apocarchesium rosettum collected from Guangzhou, in southern China; arrows indicate a helically contractile spasmoneme within the stalk (a) and a macrozooid in the colony (b). (c, d) C. polypinum collected from North Carolina, USA. (e, f) Epicarchesium abrae from Qingdao, China. (g, h, i) Detailed arrangement of infundibular polykineties of C. polypinum (g; redrawn from Lom, 1964), Epicarchesium abrae (h; redrawn from Ji et al., 2004) and Apocarchesium rosettum (i; redrawn from Ji \& Kusuoka, 2009). Arrow with numbers indicates numbering convention for polykineties and rows of kinetosomes within each polykinety.

Extraction and sequencing of DNA. Genomic DNA was extracted following the methods of Clamp \& Williams (2006). The SSU rRNA gene was amplified by PCR using the eukaryotic universal primers A forward (5'-CTGGTTGATCCTGCCAG-3 $\left.3^{\prime}\right)$ and $\mathrm{B}$ reverse (5'TGATCCTTCTGCAGGTTCACCTAC-3') (Medlin et al., 1988). PCR cycling conditions for amplification of the SSU rRNA gene were as follows: 1 cycle of $94{ }^{\circ} \mathrm{C}$ for $1 \mathrm{~min}$ followed by 30 cycles of $94{ }^{\circ} \mathrm{C}$ for $15 \mathrm{~s}, 63{ }^{\circ} \mathrm{C}$ for $1.5 \mathrm{~min}$ and $72{ }^{\circ} \mathrm{C}$ for $2.5 \mathrm{~min}$ and 1 cycle of $72{ }^{\circ} \mathrm{C}$ for $5 \mathrm{~min}$. The ITS1-5.8S-ITS2 region was amplified using the ITS-forward (5'-GTTCCCCTTGAACGAGGAATTC- $\left.3^{\prime}\right)$ and ITSreverse $\left(5^{\prime}\right.$-TACTGATATGCTTAAGTTCAGCGG-3') primers, which are complementary to conserved regions and encompass the $3^{\prime}$ end of the SSU rRNA gene, the whole of the ITS1-5.8S-ITS2 region and the $5^{\prime}$ end of the large subunit rRNA gene (Diggles \& Adlard, 1997; Goggin \& Murphy, 2000). Cycling parameters were as follows: 1 cycle of $94{ }^{\circ} \mathrm{C}$ for $1 \mathrm{~min}, 30$ cycles of $94{ }^{\circ} \mathrm{C}$ for $15 \mathrm{~s}, 63{ }^{\circ} \mathrm{C}$ for $30 \mathrm{~s}$ and $72{ }^{\circ} \mathrm{C}$ for $1 \mathrm{~min}$ and 1 cycle of $72{ }^{\circ} \mathrm{C}$ for $5 \mathrm{~min}$. The PCR products were cleaned by filtration using a QIAquick PCR Purification kit (Qiagen) and sequenced in both directions by the Duke University IGSP DNA Sequencing Facility (Durham, NC, USA) using an ABI 3730-XL DNA Analyzer (Applied Biosystems). Sequence fragments were assembled into contiguous sequences and edited using Sequencher 4.0 software (Gene Codes).
Phylogenetic analyses. Accession numbers for the SSU rRNA gene sequences determined in the present study are shown in Table 2. SSU rRNA gene sequences of other peritrichs included in the phylogenetic analyses were obtained from GenBank. These include the SSU rRNA gene sequences of (with corresponding accession numbers): Vorticella HCB (DQ487201), V. fusca (DQ190468), V. convallaria (DQ868348), V. campanula (DQ662849), V. microstoma (DQ868347), V. gracilis (GQ872429), Pseudovorticella sinensis (DQ845295), Opisthonecta minima (EF417834), O. henneguyi (X56531), Astylozoon enriquesi (AY049000), Carchesium polypinum (AB074079, AF401522), Zoothamnium arbuscula (AF401523), Z. pelagicum (DQ868351), Z. niveum (DQ868350), Z. duplicatum (DQ662851), Z. parabuscula (DQ662853), Zoothamnium sp. JCC-2006-2 (DQ868354), Zoothamnium sp. JCC2006-4 (DQ868355), Zoothamnium sp. JCC-2006-5 (DQ868356), Zoothamnium sp. JCC-2006-1 (DQ868353), Epistylis chrysemydis (AF429887), E. hentscheli (AF429889), E. plicatilis (AF335517), E. urceolata (AF335516), E. wenrichi (AF335515), E. galea (AF401527), Vaginicola crystallina (AF401521), Opercularia microdiscum (AF401525) and Campanella umbellaria (AF429885). Five members of the subclass Hymenostomatia, the closest phylogenetic relative of the subclass Peritrichia, were used as outgroup species. These were Tetrahymena corlissi (U17356), Tetrahymena bergeri (AF364039), Colpidium campylum (X56532), Ophryoglena catenula (U17355) and 
Table 1. Names and collection data of newly sequenced peritrich ciliate isolates of the genera Vorticella, Carchesium and Apocarchesium

\begin{tabular}{|llcl|}
\hline Species & \multicolumn{1}{c|}{ Origin } & Collector & Date Collected \\
\hline Vorticella sp1 & Morehead City, NC, USA & J.C. \& P.S. & $08 / 11 / 08$ \\
Vorticella sp2 & Durham, NC, USA & J.C. & $12 / 03 / 08$ \\
Vorticella sp3 & Durham, NC, USA & J.C. \& P.S. & $01 / 27 / 02$ \\
Vorticella sp4 & Jones Lake State Park, NC, USA & $02 / 23 / 08$ \\
Vorticella sp5 & Jones Lake State Park, NC, USA & J.C. \& P.S. & $02 / 23 / 08$ \\
C. polypinum popI & Eno River State Park, NC, USA & J.C. \& P.S. & $11 / 02 / 08$ \\
C. polypinum popII & Durham, NC, USA & J.C. & $02 / 03 / 09$ \\
C. polypinum popIII & Guangzhou, China & P.S. & $06 / 13 / 09$ \\
C. polypinum popIV & Mano, Japan & J.C. & $05 / 06 / 08$ \\
C. polypinum popV & Durham, NC, USA & Y. K. & $05 / 11 / 08$ \\
C. polypinum popVI & Great Smoky Mt. National Park, NC, USA & P.S. & $05 / 06 / 08$ \\
A. rosettum popI & Guangzhou, China & P.S. & J.C. \\
A. rosettum popII & Lake Biwa, Japan & Y. K. & $06 / 13 / 09$ \\
A. rosettum popIII & Lake Biwa, Japan & Y. K. & $08 / 29 / 06$ \\
A. rosettum popIV & Rolesville, NC, USA & J.C. & $08 / 29 / 06$ \\
\hline
\end{tabular}

Ichthyophthirius multifiliis (U17354). All available SSU rRNA gene sequences of species of the newly recognized subclass Mobilia were also included in phylogenetic analyses. These species were as follows: Trichodina ruditapicis (FJ499385), Trichodina sinonovaculae (FJ499386), Trichodina meretricis (FJ499387), Trichodina heterodentata (AY788099), Trichodina nobilis (AY102172), Trichodina sinipercae (EF599288), Trichodina reticulata (AY741784), Trichodina hypsilepis (EF524724) and Urceolaria urechi (FJ499388).

Sequences were aligned using the CLUSTAL w program (Thompson et al., 1997) in BioEdit version 7.0.9 software and adjusted by eye (Hall, 1999; Tamura et al., 2007). Bayesian (BI) analysis based on SSU rRNA gene sequences was performed with MrBayes 3.1.2 software (Ronquist \& Huelsenbeck, 2003) using the GTR + I + G model of sequence evolution selected by the MrModeltest 2 program (Nylander, 2004) under the AIC criterion. Four simultaneous Markov chain Monte Carlo (MCMC) chains were run for 1000000 generations, sampling every 100 generations. The first 2500 trees were discarded as burn-in. The $50 \%$ majority-rule consensus tree was determined to calculate the posterior probabilities for each node. The appropriate $\mathrm{GTR}+\mathrm{I}+\mathrm{G}$ model for maximum-likelihood (ML) analysis was selected by the MrModeltest 2 program. ML trees inferred from SSU rRNA gene sequences were reconstructed with the PhyML 3.0 program (http://www.phylogeny.fr/phylo_cgi/phyml.cgi) (Guindon et al., 2005), which performed ML analysis with heuristic searches and a 100-fold bootstrap analysis. The maximum-parsimony (MP) and neighbour-joining (NJ) analyses were performed with PAUP $^{*} 4.0 \mathrm{~b} 10$ software (Swofford, 2002) and support for the internal branches was estimated using the bootstrap method with 1000 replicates (Felsenstein, 1985).

Secondary structures of the ITS2 region of 21 strains were established with the MFOLD 3.2 program (http://mfold.rna.albany.edu/?q=mfold/ RNA-Folding-Form) (Zuker, 2003) using the default values to guide reliable sequence alignment for phylogenetic analyses. Sequences of ITS2 regions expressed in secondary-structure format were aligned using the 4SALE program (Seibel et al., 2006) based on both the primary and secondary structures. Aligned structural and sequence matrices were analysed using the same methods as described above. Bayesian analyses were performed with the following evolutionary models: GTR + I + G model for SSU rRNA gene sequences, GTR + G model for ITS1-5.8S-ITS2 region sequences and HKY $+\mathrm{G}$ model for ITS2 region sequences. For the two combined datasets (SSU rRNA+ITS1-5.8SITS2 and SSU rRNA + ITS2), individual coding regions were treated as unlinked so that separated parameter estimates, as specified above, were obtained for each region for all runs. ML, MP and NJ analyses were performed with the same methods as described above.

\section{RESULTS}

\section{Sequence comparisons}

Fifteen novel SSU rRNA gene sequences were obtained from seven species belonging to three morphologically diverse genera within the family Vorticellidae (Table 2). As shown in Table 3, the novel SSU rRNA gene sequences of six isolates of $C$. polypinum from three geographically distant localities (USA, China and Japan) shared similarities of 99.4-99.9\%. Two other SSU rRNA gene sequences of $C$. polypinum were obtained from GenBank with the following accession numbers: AB074079 (926 bp) and AF401522 (1729 bp). There were significant differences between the sequences of these two strains and those of the other six isolates (Supplementary Fig. S1) with sequence similarities of $79.1-79.4 \%$ and $94.2-94.3 \%$ to C. polypinum $\mathrm{AB} 074079$ and C. polypinum AF401522, respectively. Sequence lengths and $\mathrm{G}+\mathrm{C}$ contents of the novel SSU rRNA gene sequences are shown in Table 2.

All ITS1-5.8S-ITS2 region sequences of peritrichs that were available from GenBank were included in our phylogenetic analyses (Table 2). Entire ITS1-5.8S-ITS2 region sequences showed relatively low variation in length among the 15 taxa studied, from 415 bp in Vorticella sp2 to $437 \mathrm{bp}$ in Zoothamnium alternans (Table 2). In contrast, the $\mathrm{G}+\mathrm{C}$ contents of entire ITS1-5.8S-ITS2 region sequences varied greatly, from $30.9 \%$ in $Z$. alternans to $42.0 \%$ in Pseudovorticella punctata (Table 2).

\section{Phylogenetic analyses based on SSU rRNA gene sequences}

When included in phylogenetic analyses, the branches representing the two sequences of $C$. polypinum obtained 
Table 2. Details of sequences of members of the genera Vorticella, Carchesium, Apocarchesium, Pseudovorticella, Epicarchesium and Zoothamnium used in this study

Isolates used in this study, from which sequences were obtained, are shown in bold type. All other sequences were obtained from GenBank

\begin{tabular}{|c|c|c|c|c|c|c|}
\hline \multirow[b]{2}{*}{ Isolate/species } & \multicolumn{3}{|c|}{ SSU rRNA gene } & \multicolumn{3}{|c|}{ ITS1-5.8S-ITS2 region } \\
\hline & Accession no. & Length (bp) & $\begin{array}{c}\text { DNA G }+ \text { C content } \\
(\%)\end{array}$ & Accession no. & Length (bp) & $\begin{array}{c}\text { DNA G }+ \text { C content } \\
(\%)\end{array}$ \\
\hline Vorticella sp1 & GU987024 & 1668 & 42.33 & GU987037 & 416 & 41.83 \\
\hline Vorticella sp2 & GU187049 & 1656 & 42.39 & GU586177 & 415 & 41.20 \\
\hline Vorticella sp3 & GU187050 & 1653 & 42.35 & GU586185 & 426 & 33.80 \\
\hline C. polypinum popI & GU187053 & 1673 & 42.50 & GU082379 & 422 & 39.10 \\
\hline C. polypinum popII & GU187054 & 1681 & 42.53 & GU082380 & 422 & 40.28 \\
\hline C. polypinum popIII & GU187055 & 1673 & 42.48 & GU082381 & 422 & 39.10 \\
\hline C. polypinum popIV & GU987027 & 1666 & 42.38 & GU987034 & 422 & 39.57 \\
\hline C. polypinum popV & GU987025 & 1677 & 43.35 & GU987035 & 422 & 40.28 \\
\hline A. rosettum popIV & GU987030 & 1674 & 42.43 & GU987033 & 430 & 32.56 \\
\hline P. paracratera & DQ662847 & 1650 & 43.03 & EU340855 & 416 & 39.66 \\
\hline P. punctata & DQ190466 & 1754 & 43.67 & EU340856 & 419 & 42.00 \\
\hline E. abrae & DQ190462 & 1737 & 42.83 & EU340854 & 418 & 40.19 \\
\hline Z. alternans & DQ662850 & 1732 & 42.03 & EU340857 & 437 & 30.89 \\
\hline Z. nii & DQ662852 & 1651 & 43.31 & EU340859 & 423 & 34.04 \\
\hline Z. sinica & DQ190469 & 1733 & 42.35 & EU340861 & 422 & 34.12 \\
\hline
\end{tabular}

from GenBank (AB074079 and AF401522) were extremely long and in positions distant from other sequences of $C$. polypinum outside the vorticellid clade altogether (Supplementary Fig. S2, arrow and double arrowheads). The two C. polypinum sequences from GenBank were not included in the final phylogenetic analyses due to their significant

Table 3. SSU rRNA gene sequence similarities between populations of Carchesium polypinum

Populations: 1, popI; 2, popII; 3, popIII; 4, popIV; 5, popV; 6, popVI; 7, C. polypinum sp. (AF401522); 8, C. polypinum sp. (AB074079). Sequences for 1-6 obtained in this study; sequences for 7-8 obtained from GenBank. Values were determined by the Kimura twoparameter distance method (Kimura, 1980) and are expressed as percentages.

\begin{tabular}{|lrrrcccc|}
\hline Pop. & \multicolumn{1}{c}{$\mathbf{1}$} & $\mathbf{2}$ & $\mathbf{3}$ & $\mathbf{4}$ & $\mathbf{5}$ & $\mathbf{6}$ & $\mathbf{7}$ \\
\hline 1 & \multicolumn{1}{c}{-} & & & & & & \\
2 & 100.00 & - & & & & & \\
3 & 99.29 & 99.29 & - & & & & \\
4 & 99.39 & 99.39 & 99.90 & - & & & \\
5 & 100.00 & 100.00 & 99.29 & 99.39 & - & & \\
6 & 99.90 & 99.90 & 99.39 & 99.50 & 99.90 & - & \\
7 & 94.21 & 94.21 & 94.21 & 94.31 & 94.21 & 94.31 & - \\
8 & 79.36 & 79.36 & 79.13 & 79.26 & 79.36 & 79.26 & 78.11 \\
\hline
\end{tabular}

distances from, and sequence dissimilarities (Supplementary Fig. S1; Table 3) to, the novel sequences obtained in this study from other populations of C. polypinum. Although the overall topology did not differ in the resulting trees (Fig. 2), Bayesian support and bootstrap support did differ. In general, support values of the second subset were higher (Fig. 2).

The phylogenetic trees constructed with $\mathrm{BI}, \mathrm{ML}, \mathrm{MP}$ and NJ methods all had a similar topology (Fig. 2) and the monophyly of the subclass Peritrichia was strongly supported. The family Vorticellidae included two stable clades, however, which were well supported in all analyses by a posterior probability of 1.00 (BI) and bootstrap values of 0.81 (ML), $0.80(\mathrm{NJ})$ and 0.98 (MP) (Fig. 2). One clade contained all members of the genera Vorticella (except $V$. microstoma) and Carchesium used in this study, which grouped as a well-supported, relatively stable assemblage in all trees. Another clade consisted of members of the genera Pseudovorticella and Epicarchesium and was supported by a maximum posterior probability of 1.00 (BI) but had variable bootstrap values of $0.89(\mathrm{ML}), 0.93(\mathrm{NJ})$ and 0.51 (MP). The newly established genus Apocarchesium (Ji \& Kusuoka, 2009) was invariably a sister taxon to the clade containing members of the genera Pseudovorticella and Epicarchesium at a very deep level within the family Vorticellidae, which was well supported (1.00, BI; 0.98, ML; $0.99, \mathrm{NJ}$ and $0.98, \mathrm{MP}$ ) in all trees. 


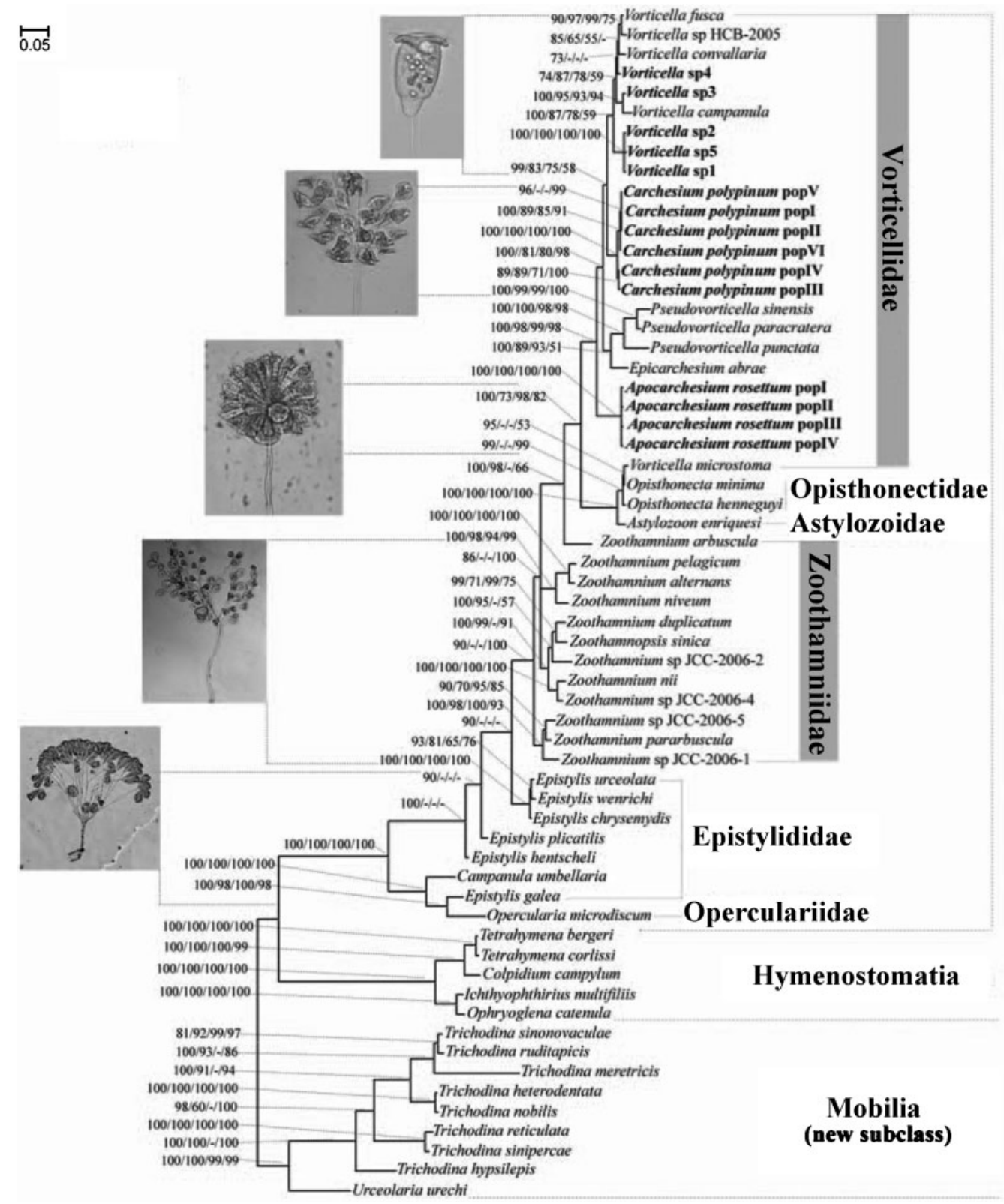

\section{Peritrichia (Sessilid)}

Fig. 2. Consensus tree formed from trees constructed with BI, ML, NJ and MP methods using SSU rRNA sequences. Species sequenced in the present study are shown in bold type. Numbers given at nodes of branches are the posterior probability value (BI) and bootstrap values (ML, NJ and MP), respectively; a dash (-) indicates nodes that were present in the Bl analyses but not in one or more of the ML, NJ or MP trees. Bar, 0.05 substitutions per nucleotide position. Classification of species follows Lynn (2008).

\section{Phylogenetic relationships between members of the genera Carchesium, Epicarchesium and Apocarchesium inferred from single and combined datasets}

Analysis of matrices of combined primary sequences and secondary structures of either the ITS1-5.8S-ITS2 region or ITS2 region alone (Fig. 3a, b) yielded a topology that was similar to analyses based on SSU rRNA gene sequences and had bootstrap values higher than those obtained with ITS1-5.8S-ITS2 or ITS2 primary sequences alone (data not shown). The following descriptions refer to the topology of trees resulting from combined primary sequences and secondary structures of ITS1-5.8S-ITS2 and ITS2 regions (Fig. 3a, b). In the ITS2 tree (Fig. 3a), Vorticella sp1 and 5 were more closely associated with $C$. polypinum and Epicarchesium abrae than other members of the genus Vorticella but in the ITS1-5.8S-ITS2 tree (Fig. 3b) Vorticella sp1 and 5 were in a clade with all members of the genera Vorticella and Pseudovorticella, only with very poor support. 

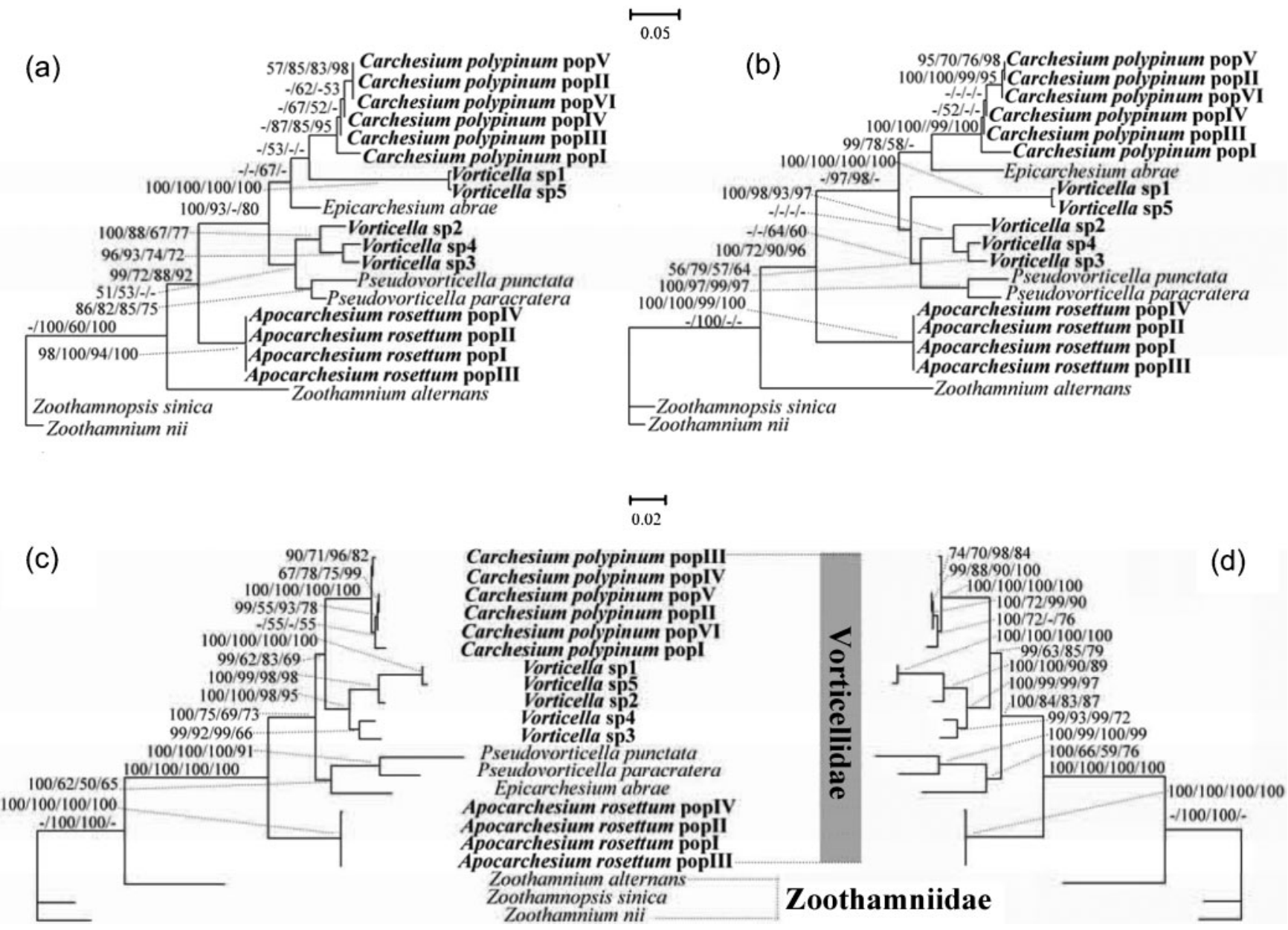

Fig. 3. Consensus trees constructed with $\mathrm{BI}, \mathrm{ML}, \mathrm{NJ}$ and MP methods showing phylogenetic relationships among species of the genera Carchesium, Epicarchesium and Apocarchesium. $(\mathrm{a}, \mathrm{b})$ Phylogenies inferred from ITS2 sequences and ITS1-5.8SITS2 sequences alone. (c, d) Phylogenies inferred from one combined dataset consisting of concatenated SSU rRNA and ITS2 sequences and another combined dataset consisting of concatenated SSU rRNA and ITS1-5.8S-ITS2 sequences. Species sequenced in the present study are shown in bold type. Numbers given at nodes of branches are the posterior probability (BI) and bootstrap values (ML, NJ and MP), respectively; a dash (-) indicates branch positions that differed or were absent in one or more of the $\mathrm{BI}, \mathrm{ML}, \mathrm{NJ}$ and MP phylogenies. Bars, 0.05 and 0.02 substitutions per nucleotide position, for (a, b) and (c, d) respectively. Classification of species follows Lynn (2008).

Compared with those constructed from single datasets (either the ITS1-5.8S-ITS2 region or the ITS2 region alone; Fig. 3a, b), phylogenies of the 21 strains from families Vorticellidae and Zoothamniidae inferred from combined datasets (either SSU rRNA+ITS2 or SSU rRNA + ITS1-5.8S-ITS2) had a similar topology with relatively higher levels of bootstrap support for the branches (Fig. 3c, d), even though branch lengths differed somewhat between analyses (data not shown). In all trees, all species of the family Vorticellidae formed a monophyletic clade that was clearly separated from the family Zoothamniidae (Fig. 3). The genus Apocarchesium was distant from the clade containing the genus Carchesium and was strongly supported as a sister taxon to the Pseudovorticella-Epicarchesium clade (Fig. 3c, d).

\section{DISCUSSION}

\section{Phylogenetic relationships within the family Vorticellidae}

Previous studies showed that Vorticella microstoma always clustered with the clade containing species of the genera Opisthonecta and Astylozoon, rather than with its morphological relatives (Miao et al., 2001, 2004; Williams \& Clamp, 2007; Utz \& Eizirik, 2007; Li et al., 2008). In the trees based on SSU rRNA gene sequences, $V$. microstoma grouped with the clade containing the species Opisthonecta minima, Opisthonecta henneguyi and Astylozoon enriquesi and was distant from other species of the genus Vorticella, supported by variable bootstrap values. The SSU rRNA gene sequence 
of $V$. microstoma differed from that of O. minima and $O$. henneguyi by only seven and 12 sites, respectively, and the evolutionary similarity between $V$. microstoma and two species of the genus Opisthonecta was so high (Supplementary Fig. S2) that it can be concluded that there is a close evolutionary relationship between these taxa. The presence of a number of specific similarities between semi-conserved regions of the SSU rRNA gene sequence alignments (Williams \& Clamp, 2007) further supported this hypothesis; however, this analysis is based on a relatively small number of sequences. Work is in progress to analyse a larger set of samples of $V$. microstoma, other morphologically similar species of the genus Vorticella and other opisthonectid and astylozoid peritrichs to clarify placement of this clade within the subclass Peritrichia.

The relationship between the four genera Vorticella, Carchesium, Pseudovorticella and Epicarchesium has been questioned by previous molecular studies (Clamp \& Williams, 2006; Utz \& Eizirik, 2007; Li et al., 2008). Miao et al. (2004) first found a close association between the species C. polypinum and $Z$. arbuscula in phylogenetic trees based on SSU rRNA gene sequences. Later, Li et al. (2008) included species of the genera Epicarchesium and Pseudovorticella in phylogenetic analyses and found that these two genera were grouped as a monophyletic clade, which appeared to confirm that, in this case, the silverline system was a reliable morphological characteristic for identifying taxonomic groups at the generic level. However, C. polypinum was still associated with $Z$. arbuscula rather than species of the genus Vorticella in these analyses, as was the case in all previous studies (Clamp \& Williams, 2006; Utz \& Eizirik, 2007; Li et al.,
2008). In our analyses, we included novel SSU rRNA gene sequences of six populations of $C$. polypinum and five species of the genus Vorticella. In all of the resultant trees, the novel sequences of $C$. polypinum always clustered with the species of the genus Vorticella, except for $V$. microstoma, forming a well-supported sister group to the clade containing members of the genera Pseudovorticella and Epicarchesium. This supports the separation of vorticellids with a reticulate silverline system from other vorticellids (Figs 2 and 4 ) and suggests that a reticulate silverline system is a synapomorphic characteristic within the family Vorticellidae. Also, our results suggest that the colonial mode of development may be a plesiomorphic characteristic relative to the solitary mode of development (Figs 2 and 4).

Apocarchesium is the first genus of colonial peritrichs to have been defined based on differences in the mode of development of the colony. At first glance, Apocarchesium rosettum (Fig. 3a) appears to be merely a species of the genus Carchesium in which development of the colony has been arrested before the formation of secondary branches. Indeed, Colonies of $C$. polypinum pass through a similar stage early in their development. Therefore, does $A$. rosettum represent a developmental variant of the genus Carchesium or does it represent a separate, evolutionarily divergent genus? The present study provides the first opportunity to test these hypotheses with molecular data.

In all of the trees, A. rosettum was basal to the two major clades of vorticellids and was distant from C. polypinum. Moreover, this relationship was strongly supported by bootstrap analyses. These results strongly support the

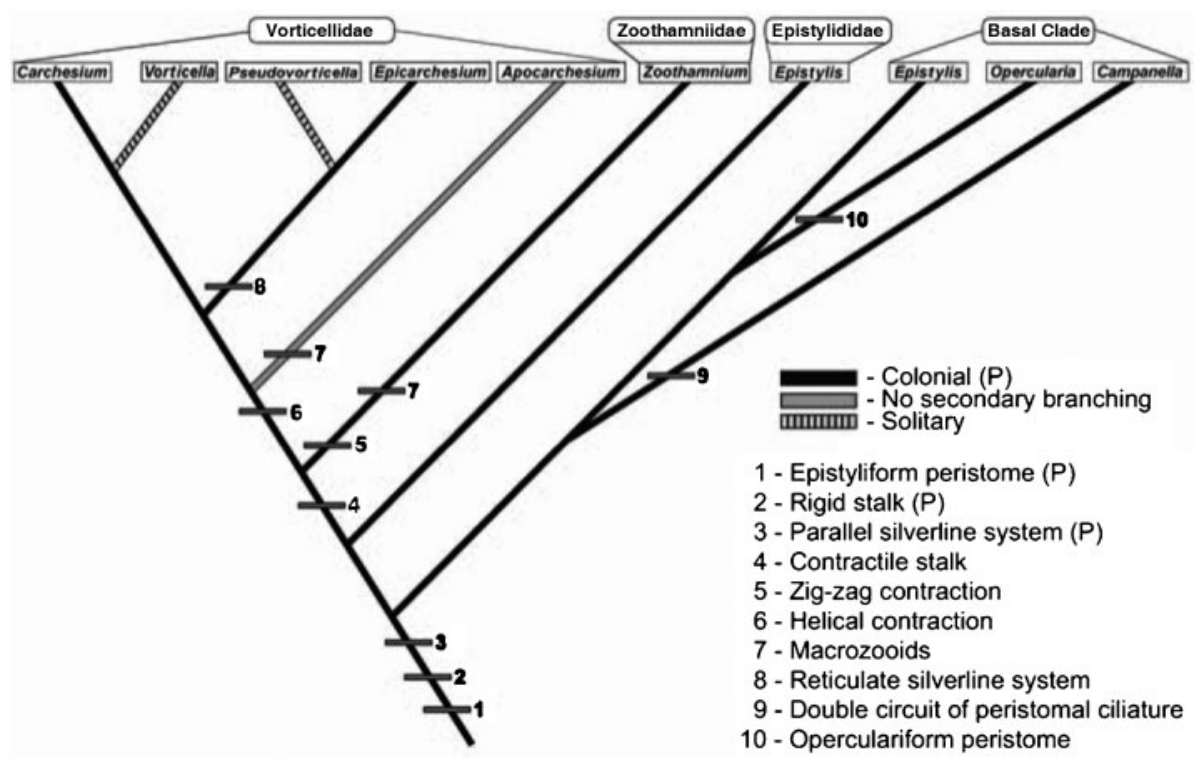

Fig. 4. Morphological and developmental characteristics of selected genera of peritrichs investigated in the present study mapped onto a simplified version of the molecular phylogeny. $(P)$, plesiomorphic characters; other characters are apomorphies for the branch or clade to which they lead. 
validity of the genus Apocarchesium. The basal phylogenetic position of $A$. rosettum relative to all 'traditional' vorticellids (i.e. species that meet the classical morphological criterion of having a helically contractile stalk), however, may indicate that the lack of branching seen in Apocarchesium is a truly plesiomorphic characteristic. Alternatively it may be a feature that evolved following its divergence from the common ancestor of 'traditional' vorticellids. The former conclusion would seem to be the favoured one since no members of other major genera of colonial peritrichs (Zoothamnium and Epistylis) that occupy a more basal position than vorticellids within the subclass Peritrichia have the lack of branching seen in the genus Apocarchesium (Fig. 4).

Besides the unique morphology of the colony in A. rosettum, it is characterized by having macrozooids (Fig. 3b, arrows), a developmental characteristic not yet reported in other colonial vorticellids but typical of some members of the genus Zoothamnium. Therefore, we also included three species of zoothamniid, one of which also harbours macrozooids in its colonies, in our analyses. None of the trees displayed any close relationship between A. rosettum and the zoothamniids, indicating that the possession of macrozooids is probably a convergent characteristic of the two taxa and, thus, represents a probable synapomorphy wherever it occurs in the phylogeny (Fig. 4).

\section{Phylogenetic relationships of the morphologically similar genera Carchesium, Epicarchesium and Apocarchesium determined using different datasets}

The topology of the trees constructed from combined datasets (SSU rRNA + ITS1-5.8S-ITS2 and SSU rRNA + ITS2) was similar to that inferred from SSU rRNA sequences alone (Fig. $3 c, d)$. This might be attributed to the much greater length of the SSU rRNA sequences used, which consequently contained larger amounts of information compared with those of the ITS2 and ITS1-5.8S-ITS2 regions. However, it was also apparent that a tree based on sequences of the ITS1-5.8SITS2 region had a topology similar to that seen in trees reconstructed using sequences of the ITS2 region alone, only with relatively higher supporting values (Fig. 3a, b). Thus, the clearest separation of the three genera was obtained by analysing a combined dataset composed of SSU rRNA gene and ITS1-5.8S-ITS2 region sequences (Fig. 3d). These results indicate that phylogenies based on combined datasets, which contain a larger number and greater variety of informative sites, are more effective than phylogenies based on single datasets in explaining the evolutionary history of peritrichs, especially if a progressively broader and more representative array of taxa is included.

\section{ACKNOWLEDGEMENTS}

This work was supported by a grant from the National Science Foundation (grant no. DEB-0716348). We wish to thank Dr Xiaofeng
Lin, Laboratory of Protozoology, South China Normal University (SCNU), Guangzhou, China, for institutional support. Part of this work was funded by the Lake Biwa Museum Comprehensive Research Project S06-02 and the Grant-In-Aid for Scientific Research (B) No. 21310024 from the Japan Society for the Promotion of Science. The help of Mr Li Bo and Mr Shi Xiaokun, graduate students at SCNU, was invaluable during sample collection.

\section{REFERENCES}

Clamp, J. C. \& Williams, D. (2006). A molecular phylogenetic investigation of Zoothamnium (Ciliophora, Peritrichia, Sessilida). J Eukaryot Microbiol 53, 494-498.

Coleman, A. W. (2005). Paramecium aurelia revisited. J Eukaryot Microbiol 52, 68-77.

Corliss, J. O. (1979). The Ciliated Protozoa: Characterization, Classification and Guide to the Literature. Oxford: Pergamon Press.

Diggles, B. K. \& Adlard, R. D. (1997). Intraspecific variation in Cryptocaryon irritans. J Eukaryot Microbiol 44, 25-32.

Ehrenberg, C. G. (1831). [Über die Entwicklung und Lebensdauer der Infusionsthiere; nebst ferneren Beiträgen zu einer Vergleichung ihrer Organischen Systeme]. Abh Akad Wiss Berlin, 1-154 (in German).

Felsenstein, J. (1985). Confidence limits on phylogenies: an approach using the bootstrap. Evolution 39, 783-791.

Foissner, W. \& Schiffmann, H. (1974). [Vergleichende Studien an argyrophilen Strukturen von vierzehn peritrichen Ciliaten]. Protistologica (Paris) 10, 489-508 (in German).

Goggin, C. L. \& Murphy, N. E. (2000). Conservation of sequence in the internal transcribed spacers and $5.8 \mathrm{~S}$ ribosomal RNA among geographically separated isolates of parasitic scuticociliates (Ciliophora, Orchitophryidae). Dis Aquat Organ 40, 79-83.

Gong, Y. C., Yu, Y. H., Villalobo, E., Zhu, F. Y. \& Miao, W. (2006). Reevaluation of the phylogenetic relationship between mobilid and sessilid peritrichs (Ciliophora, Oligohymenophorea) based on small subunit rRNA gene sequences. J Eukaryot Microbiol 53, 397-403.

Guindon, S., Lethiec, F., Duroux, P. \& Gascuel, O. (2005). PHYML Online-a web server for fast maximum likelihood-based phylogenetic inference. Nucleic Acids Res 33 (Web Server), W557-W559.

Hall, T. A. (1999). BioEdit: a user-friendly biological sequence alignment editor and analysis program for Windows 95/98/NT. Nucleic Acids Symp Ser 41, 95-98.

Jankowski, A. W. (1975). Account of Scientific Sessions on Results of Scientific Work, Year 1974, Abstracts of Reports, pp. 26-27. Edited by U. S. Balashov. Leningrad: Akad Nauk SSSR, Zool Inst.

Ji, D. \& Kusuoka, Y. (2009). A description of Apocarchesium rosettum n. gen., n. sp. and a redescription of Ophrydium eichornii Ehrenberg, 1838, two freshwater peritrichous ciliates from Japan. Eur J Protistol $45,21-28$.

Ji, D., Song, W. \& Warren, A. (2004). Rediscovery and redescription of the marine peritrichous ciliate Epicarchesium abrae (Precht, 1935) nov. comb. (Protozoa, Ciliophora, Peritrichia). Eur J Protistol 40, 219-224.

Kahl, A. (1935). [Urtiere oder Protozoa I: Wimpertiere oder Ciliata (Infusoria). 4. Peritricha und Chonotricha]. Tierwelt Dtl 30, 651-886 (in German).

Kimura, M. (1980). A simple method for estimating evolutionary rates of base substitutions through comparative studies of nucleotide sequences. J Mol Evol 16, 111-120.

Leitner, A. R. \& Foissner, W. (1997). Taxonomic characterization of Epicarchesium granulatum (Kellicott, 1887) Jankowki, 1985 and 
Pseudovorticella elongata (Fromentel, 1876) nov. comb., two peritrichs (Protozoa, Ciliophora) from activated sludge. Eur J Protistol 33, 13-29.

Li, L., Song, W. B., Warren, A., Shin, M. K., Chen, Z. G., Ji, D. D. \& Sun, P. (2008). Reconsideration of the phylogenetic positions of five peritrich genera, Vorticella, Pseudovorticella, Zoothamnopsis, Zoothamnium, and Epicarchesium (Ciliophora, Peritrichia, Sessilida), based on small subunit rRNA gene sequences. J Eukaryot Microbiol 55, 448-456.

Lom, J. (1964). The morphology and morphogenesis of the buccal ciliary organelles in some peritrichous ciliates. Arch Protistenkd 107, 131-162.

Lynn, D. H. (2008). The Ciliated Protozoa. Characterization, Classification, and Guide to the Literature, 3rd edn. Dordrecht: Springer.

Medlin, L., Elwood, H. J., Stickel, S. \& Sogin, M. L. (1988). The characterization of enzymatically amplified eukaryotic 16S-like rRNA-coding regions. Gene 71, 491-499.

Miao, M., Warren, A., Song, W., Wang, S., Shang, H. \& Chen, Z. (2008). Analysis of the internal transcribed spacer 2 (ITS2) region of scuticocillates and related taxa (Clliophora, Oligohemenophorea) to infer their evolution and phylogeny. Protist 159, 519-533.

Miao, W., Yu, Y. H. \& Shen, Y. F. (2001). Phylogenetic relationships of the subclass Peritrichia (Oligohymenophorea, Ciliophora) with emphasis on the genus Epistylis, inferred from small subunit rRNA gene sequences. J Eukaryot Microbiol 48, 583-587.

Miao, W., Fen, W. S., Yu, Y. H., Zhang, X. Y. \& Shen, Y. F. (2004). Phylogenetic relationships of the subclass Peritrichia (Oligohymenophorea, Ciliophora) inferred from small subunit rRNA gene sequences. J Eukaryot Microbiol 51, 180-186.

Nylander, J. (2004). Mr Modeltest Version 2. Distributed by the Author. Uppsala, Sweden: Department of Systematic Zoology, Evolutionary Biology Centre, Uppsala University.

Ronquist, F. \& Huelsenbeck, J. P. (2003). MrBayes 3: Bayesian phylogenetic inference under mixed models. Bioinformatics 19, 1572-1574.
Seibel, P. N., Müller, T., Dandekar, T., Schultz, J. \& Wolf, M. (2006). 4SALE-a tool for synchronous RNA sequence and secondary structure alignment and editing. BMC Bioinformatics 7, 498.

Shimodaira, H. \& Hasegawa, M. (1999). Multiple comparisons of log-likelihoods with applications to phylogenetic inference. Mol Biol Evol 16, 1114-1116.

Swofford, D. L. (2002). PAUP* Phylogenetic analysis using parsimony (and other methods). Version 4. Sinauer Associates.

Tamura, K., Dudley, J., Nei, M. \& Kumar, S. (2007). MEGA4: molecular evolutionary genetics analysis (MEGA) software version 4.0. Mol Biol Evol 24, 1596-1599.

Thompson, J. D., Gibson, T. J., Plewniak, F., Jeanmougin, F. \& Higgins, D. G. (1997). The CLUSTAL_X windows interface: flexible strategies for multiple sequence alignment aided by quality analysis tools. Nucleic Acids Res 25, 4876-4882.

Utz, L. R. P. \& Eizirik, E. (2007). Molecular phylogenetics of subclass Peritrichia (Ciliophora: Oligohymenophorea) based on expanded analyses of $18 \mathrm{~S}$ rRNA sequences. J Eukaryot Microbiol 54, 303305.

Warren, A. (1986). A revision of the genus Vorticella (Ciliophora: Peritrichida). Bull Br Mus Nat Hist (Zool) 50, 1-57.

Williams, D. \& Clamp, J. C. (2007). A molecular phylogenetic investigation of Opisthonecta and related genera (Ciliophora, Peritrichia, Sessilida). J Eukaryot Microbiol 54, 317-323.

Zhan, Z. F., Xu, K. D., Warren, A. \& Gong, Y. C. (2009). Reconsideration of phylogenetic relationships of the subclass Peritrichia (Ciliophora, Oligohymenophorea) based on small subunit ribosomal RNA gene sequences, with the establishment of a new subclass Mobilia Kahl, 1933. J Eukaryot Microbiol 56, 552-558.

Zuker, M. (2003). Mfold web server for nucleic acid folding and hybridization prediction. Nucleic Acids Res 31, 3406-3415. 